\title{
The major types of added sugars and non-nutritive sweeteners in a sample of Australian packaged foods
}

\author{
Yasmine C Probst ${ }^{1,2}$, Alexis Dengate ${ }^{1}$, Jenny Jacobs ${ }^{1}$, Jimmy CY Lovie ${ }^{3,4}$ and \\ Elizabeth K Dunford ${ }^{5,6, *}$
}

'School of Medicine, Faculty of Science Medicine and Health, University of Wollongong, Wollongong, NSW, Australia: ${ }^{2}$ Illawarra Health and Medical Research Institute, Wollongong, NSW, Australia: ${ }^{3}$ School of Life and Environmental Sciences and Charles Perkins Centre, University of Sydney, Sydney, NSW, Australia: ${ }^{4}$ School of Biological Sciences, Faculty of Science, University of Hong Kong, Hong Kong SAR, People's Republic of China: ${ }^{5}$ Food Policy Division, The George Institute for Global Health, Sydney, NSW, Australia: ${ }^{6}$ Carolina Population Center, The University of North Carolina at Chapel Hill, 137 East Franklin Street, Room 6602, Chapel Hill, NC 27516, USA

Submitted 17 April 2017: Final revision received 30 June 2017: Accepted 13 July 2017: First published online 30 August 2017

\begin{abstract}
Objective: Limiting the intake of added sugars in the diet remains a key focus of global dietary recommendations. To date there has been no systematic monitoring of the major types of added sugars used in the Australian food supply. The present study aimed to identify the most common added sugars and non-nutritive sweeteners in the Australian packaged food supply.

Design: Secondary analysis of data from the Australian FoodSwitch database was undertaken. Forty-six added sugars and eight non-nutritive sweetener types were extracted from the ingredient lists of 5744 foods across seventeen food categories. Setting: Australia.

Subjects: Not applicable.

Results: Added sugar ingredients were found in $61 \%$ of the sample of foods examined and non-nutritive sweetener ingredients were found in 69\%. Only $31 \%$ of foods contained no added sugar or non-nutritive sweetener. Sugar (as an ingredient), glucose syrup, maple syrup, maltodextrin and glucose/dextrose were the most common sugar ingredient types identified. Most Australian packaged food products had at least one added sugar ingredient, the most common being 'sugar'. Conclusions: The study provides insight into the most common types of added sugars and non-nutritive sweeteners used in the Australian food supply and is a useful baseline to monitor changes in how added sugars are used in Australian packaged foods over time.
\end{abstract}

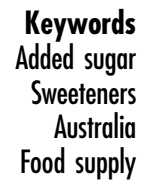

The Australian Dietary Guidelines recommend a limited consumption of added sugars ${ }^{(10)}$. Despite this, there is no official guidance on the amount of sugars that can be added to food and beverage products sold in Australia. Australian food labelling regulations require only the 'total' sugar in a product to be displayed, rather than differentiating between naturally occurring sugars and those added during the manufacturing process ${ }^{(11)}$. Furthermore, there is a myriad of terms used to describe added sugar types $^{(9)}$. This presents a significant challenge for both monitoring and use of added sugars in the Australian food supply by manufacturers ${ }^{(2)}$, and for consumers to understand what is in the foods they are buying.

Sweeteners are comprised of both nutritive sweeteners that provide energy and non-nutritive/intense sweeteners that have no caloric properties ${ }^{(12)}$. In Australia, there is a vast range of nutritive and non-nutritive sweeteners 
approved for use in food and beverage products ${ }^{(12,13)}$. Some research has suggested that consumption of nonnutritive sweeteners can have similar adverse metabolic effects to sugar intake, and they have been linked to weight gain ${ }^{(14,15)}$, metabolic syndrome ${ }^{(16)}$ and $\mathrm{CVD}^{(17)}$. However, in randomized controlled trials, the opposite association has been observed ${ }^{(18)}$. Some explanations for a potential adverse effect include mechanisms such as greater energy intake after 'saved' kilojoules due to consuming non-nutritive sweeteners ${ }^{(19)}$ and a disruption in sweet taste perception and subsequent energy intake ${ }^{(20)}$. It is therefore important to understand how prevalent both added sugars and non-nutritive sweeteners are in the food supply.

For the purposes of the present paper, the term 'added sugars' considers both nutritive sweeteners and all ingredients added as sugar to a product in line with the WHO definition of 'free sugars'. Where non-nutritive sweeteners are identified, these are referred to as such. The aim of the current study was therefore to determine the most common types of added sugars and non-nutritive sweeteners used in the Australian packaged food supply. As sugarcane is a primary crop produced in Australia, rather than corn as is seen in the USA ${ }^{(21)}$, it was hypothesized that white sugar (i.e. pure sucrose) would be the main type of added sugar used in Australian packaged foods.

\section{Methods}

The current study was a cross-sectional analysis of the Australian packaged food supply ${ }^{(22,23)}$. As a requirement of Food Standards Australia New Zealand, most packaged food items sold in Australia must carry a Nutrition Information Panel that clearly states product information such as serving size, as well as quantity of energy and nutrients per $100 \mathrm{~g}$, including total sugars ${ }^{(24)}$. Inclusion of ingredients lists declaring all ingredients used in descending order of weight is also mandatory unless the product name is the same as the statement of ingredients ${ }^{(25)}$.

\section{Data transcription}

The 2012 FoodSwitch branded food composition database $^{(21)}$, collated by The George Institute for Global Health, was used to access the food product information used for the present study. The FoodSwitch database provides photographic images of food products, their ingredient listings, Nutrition Information Panel data and assorted text-based fields for data extracted from the food product images for approximately 50000 packaged food items ${ }^{(22,23)}$. Foods are categorized into one of the approximately 650 FoodSwitch database subcategories ${ }^{(22)}$. For the purposes of the present study only food products collected in the year 2012 with an ingredients list were examined. Data for each individual food item were extracted, including the product name, product identification code, food category code, food category name, Nutrition Information Panel data per $100 \mathrm{~g}$ of product, as well as product (packaging) images from which the ingredients list was transcribed.

\section{Determining added sugar and non-nutritive sweetener types}

To determine the types of added sugar and non-nutritive sweeteners added to Australian food products, a random selection of products was taken proportionally from each major food category in the FoodSwitch database ( $n$ 5744), extracted into a Microsoft ${ }^{\circledR}$ Excel 2014 workbook and analysed. The ingredients list for each food item was searched for the presence of forty-six added sugars and eight non-nutritive sweeteners (see online supplementary material for the list of sugar descriptors). As several descriptors overlapped, coding processes were used to correctly differentiate the ingredients. For example, to prevent an overlap in added sugars and non-nutritive sweeteners for a search term that was also included within another search term (e.g. 'glucose' $v$. 'glucose syrup'), we applied a double filter in Microsoft Excel. Those that were falsely identified had their values manually changed. A double filter was also applied to added sugars and nonnutritive sweeteners that used multiple descriptors to identify the specific ingredient (e.g. 'barley malt', 'caster sugar', 'aspartame (E951)'). A single filter for the term 'caramel' was used to assist in the manual identification of products that falsely identified 'caramel colour' as 'caramel'. The word 'concentrate' was also used to ensure products identified referred only to fruit concentrate and excluded all other types of concentrates. Products falsely identified were again manually adjusted. Variations in punctuation were addressed both programmatically and manually. For example, the use of a hyphen (-) $v$. a space between words.

\section{Results}

As shown in Table 1, 3935 of the 5744 products (68.5\%) contained at least one type of added sugar or non-nutritive sweetener. Non-specified sugar was the most common added sugar found in the sample, with 3481 products (60.6\%) listing this in the ingredients list. According to the Australia New Zealand Food Standards Code, this nonspecified type refers to white sugar. This was followed by non-specified syrups, with 1074 products (18.7\%), and glucose/dextrose with 753 products (13.1\%). Of the 1074 products that contained syrup, the vast majority $(70 \cdot 1 \%)$ contained glucose syrup, followed by maple syrup (69.3\%) and golden syrup (13.9\%). Interestingly, the added sugar identified as the most common in all food groups with added sugar, other than the 'Fats and oils' and 'Vitamin and mineral supplements' food categories, was found in at least $20 \%(22 \cdot 8-87.5 \%)$ of products in the group. 
Table 1 Primary added sugars and non-nutritive sweeteners for each major food category in a sample of Australian packaged foods ( $n$ 5744), 2012

\begin{tabular}{|c|c|c|c|c|c|c|c|c|c|c|}
\hline \multirow[b]{3}{*}{ FoodSwitch food category } & \multirow[b]{3}{*}{ Products $(n)$} & \multicolumn{9}{|c|}{ Top three sweeteners } \\
\hline & & \multicolumn{3}{|l|}{1} & \multicolumn{3}{|l|}{2} & \multicolumn{3}{|c|}{3} \\
\hline & & Type & $n$ & $\% *$ & Type & $n$ & $\%^{*}$ & Type & $n$ & $\% *$ \\
\hline Bread and bakery products $\dagger$ & 1175 & Sugar (nfs) & 870 & $74 \cdot 0$ & Syrup (any) & 344 & $29 \cdot 3$ & Glucose syrup & 181 & $15 \cdot 4$ \\
\hline Cereal and cereal products $\dagger$ & 771 & Sugar (nfs) & 514 & $67 \cdot 1$ & Maltodextrin & 189 & 24.5 & Syrup & 128 & $16 \cdot 6$ \\
\hline Confectionery & 834 & Sugar (nfs) & 730 & 87.5 & Glucose/ maple syrup & 328 & $39 \cdot 3$ & Lactose & 74 & 8.9 \\
\hline Convenience foods $†$ & 266 & Sugar (nfs) & 196 & $73 \cdot 7$ & Dextrose & 44 & 16.5 & Maltodextrin & 32 & $12 \cdot 0$ \\
\hline Edible oils and oil emulsions & 76 & Maltodextrin & 2 & $2 \cdot 6$ & - & & & - & & \\
\hline Egg products and dishes & 22 & Nil sweeteners & & & - & & & - & & \\
\hline Fish products and dishes & 85 & Sugar (nfs) & 31 & $36 \cdot 5$ & $\begin{array}{l}\text { Maltodextrin } \\
\text { Glucose/dextrose }\end{array}$ & $\begin{array}{l}8 \\
8\end{array}$ & $\begin{array}{l}9 \cdot 4 \\
9 \cdot 4\end{array}$ & - & & \\
\hline Fruit, vegetables, nuts, legumes $†$ & 838 & Sugar (nfs) & 191 & $22 \cdot 8$ & $\begin{array}{l}\text { Maltodextrin } \\
\text { Glucose/dextrose }\end{array}$ & $\begin{array}{l}30 \\
30\end{array}$ & $\begin{array}{l}3.6 \\
3.6\end{array}$ & - & & \\
\hline Meat products and dishes & 299 & Sugar (nfs) & 148 & 49.5 & Glucose/dextrose & 101 & 33.8 & Maltodextrin & 58 & $19 \cdot 4$ \\
\hline Milk products and dishes & 458 & $\begin{array}{l}\text { Sugar (nfs) } \\
\text { Glucose/maple syrup }\end{array}$ & $\begin{array}{r}262 \\
81\end{array}$ & $\begin{array}{l}57 \cdot 2 \\
17 \cdot 7\end{array}$ & Glucose/dextrose & 55 & $12 \cdot 0$ & & & \\
\hline Miscellaneous & 15 & Sugar (nfs) & 8 & $53 \cdot 3$ & $\begin{array}{l}\text { Glucose/dextrose } \\
\text { Glucose/maple syrup }\end{array}$ & $\begin{array}{l}3 \\
3\end{array}$ & $\begin{array}{l}20 \cdot 0 \\
20 \cdot 0\end{array}$ & - & & \\
\hline Non-alcoholic beverages $\dagger$ & 246 & Sugar (nfs) & 81 & $32 \cdot 9$ & Glucose/dextrose & 8 & 3.3 & Cane sugar & 7 & $2 \cdot 8$ \\
\hline Sauces and spreads & 310 & Sugar (nfs) & 238 & 76.8 & Caramel & 30 & 9.7 & Maltodextrin & 21 & 6.8 \\
\hline Snack foods $\dagger$ & 155 & Sugar (nfs) & 97 & $62 \cdot 6$ & Maltodextrin & 77 & $49 \cdot 7$ & Glucose/dextrose & 38 & 24.5 \\
\hline Sugar products and dishes & 55 & Sugar (nfs) & 37 & $67 \cdot 3$ & Honey & 8 & 14.5 & $\begin{array}{l}\text { Glucose/maple } \\
\text { syrup }\end{array}$ & 6 & $10 \cdot 9$ \\
\hline Special foods incl. meal replacements & 131 & Sugar (nfs) & 42 & $32 \cdot 1$ & Maltodextrin & 34 & $26 \cdot 0$ & Fructose & 33 & $25 \cdot 2$ \\
\hline Vitamins and supplements & 8 & $\begin{array}{l}\text { Glucose/dextrose } \\
\text { Maltodextrin } \\
\text { Sucrose } \\
\text { Steviol glycoside (E960) }\end{array}$ & $\begin{array}{l}1 \\
1 \\
1 \\
1\end{array}$ & $\begin{array}{l}12 \cdot 5 \\
12.5 \\
12 \cdot 5 \\
12 \cdot 5\end{array}$ & - & & & - & & \\
\hline TOTAL & 5744 & & 3451 & $60 \cdot 0$ & & 1326 & 23.0 & & 633 & 11.0 \\
\hline
\end{tabular}

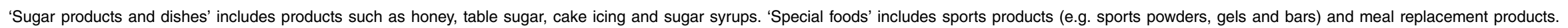
'Sugar products and dishes' includes products such as honey, table sugar, cake icing and sugar syin The 'Miscellaneous' food category includes products that fall outside other major food categories.

†Groups that contain grain/grain products or fruit/fruit products, $\mathrm{nfs}=$ not further specified. Sugar (nfs) defined as white sugar ${ }^{(25)}$. 
High-fructose corn syrup was present in only $0.6 \%(n 6)$ of the products containing syrups as ingredients. Similarly, non-nutritive sweeteners were identified as a primary sweetener type for only one of the food groups in the present study, namely 'Vitamins and supplements'.

Fourteen out of the seventeen groups had a nonspecified sugar, non-specified syrup and glucose/ dextrose, and/or maltodextrin as the main added sugar ingredient (Table 1). Of these, fourteen food groups contained white sugar as the top added sugar. Only one food group, 'Eggs and egg products', contained products with no added sugar or non-nutritive sweeteners. This category was also the third smallest of all the food groups studied. Following the 'Confectionery' (98.1\%) food category, which was expected to contain the greatest proportion of products with added sugar or non-nutritive sweeteners identified, the 'Sugar products and dishes' category contained the second greatest proportion (85.5\%), the 'Sauces and condiments' food category contained the third greatest proportion ( $81.9 \%)$, followed by 'Bread and bakery products' (79.7\%) and 'Convenience foods' (78.9\%; Table 2). Food categories not traditionally associated with added sugars such as 'Fish and fish products' and 'Meat and meat products' were also found to contain a substantial proportion of products with added sugar ingredients.

\section{Discussion}

To our knowledge, the present study is the first of its kind to investigate the major types of added sugar used in the Australian packaged food supply. Monitoring the added sugar content and types of sweeteners used in foods and beverages has been an ongoing challenge for health organizations around the world. Globally, limited research exists investigating the use of sweeteners in any national food supply ${ }^{(2,26-28)}$.

Of the 5744 products examined, the majority of products $(60 \cdot 6 \%)$ contained at least one type of added sugar, with non-nutritive sweeteners found in more than four in every six (68.8\%) products sampled. These results are in line with a recent Canadian study which found that $66 \%$ of packaged food products contained at least one added sugar ingredient ${ }^{(29)}$. As expected, the food category in the current study with the highest proportion of products containing added sugar ingredients was 'Confectionery', although surprisingly only one major food category ('Eggs and egg products') did not have any products containing added sugar ingredients. This represents a considerable proportion of Australian packaged food products. Less than one-third (31.1\%) of the foods sampled in the present study contained no added sugar or non-nutritive sweeteners. Further to this, food types not often associated with added sugars (such as fish and meat) were also found to contain added sugar ingredients, which demonstrates the many uses of these ingredients for food processing. Added sugars appear not only to exist as a sweetening agent, but they are also vital for binding, fermentation and colouring of food products which consumers may not be aware of.

The most prevalent added sugars were sugar (of any type) and syrups as a group. When compared with results from a similar investigation of the US food supply ${ }^{(2)}$, added sugar use was notably different. The US study found corn syrup to be the most common added sugar, followed by sorghum and high-fructose corn syrup, none of which were mirrored in the present Australian study. Corn syrup represented only forty-five instances of all products that contained added sugar, and high-fructose corn syrup was found in only six products $(<0.1 \%)$ overall. Furthermore, when the products were separated

Table 2 Proportion of packaged products containing added sugars (nutritive sweeteners (NS)) or non-nutritive sweeteners (NNS) in a sample of Australian packaged foods ( $n$ 5744), 2012

\begin{tabular}{|c|c|c|c|c|c|c|}
\hline FoodSwitch food category & $\begin{array}{l}\text { Products } \\
\quad(n)\end{array}$ & $\begin{array}{l}\text { Products containing } \\
\text { NS or NNS }(\%)\end{array}$ & $\begin{array}{l}\text { NS/NNS } \\
\text { types }(n)\end{array}$ & $\begin{array}{c}\text { Contains NS } \\
\text { only (\%) }\end{array}$ & $\begin{array}{c}\text { Contains NNS } \\
\text { only (\%) }\end{array}$ & $\begin{array}{l}\text { Contains NNS } \\
\text { ingredient }(n)\end{array}$ \\
\hline Fruit, vegetables, nuts, legumes & 838 & 61.9 & 23 & $28 \cdot 3$ & 0.0 & 0 \\
\hline Bread and bakery products & 1175 & $79 \cdot 7$ & 44 & 97.9 & 0.0 & 1 \\
\hline Milk products and dishes & 458 & $62 \cdot 9$ & 39 & 94.8 & 1.3 & 6 \\
\hline Cereal based products and dishes & 771 & $78 \cdot 7$ & 38 & 93.9 & $0 \cdot 1$ & 1 \\
\hline Non-alcoholic beverages & 246 & $38 \cdot 2$ & 14 & 37.4 & 0.8 & 2 \\
\hline Meat products and dishes & 299 & 68.6 & 19 & $68 \cdot 6$ & 0.0 & 0 \\
\hline Edible oils and oil emulsions & 76 & $2 \cdot 6$ & 1 & $2 \cdot 6$ & 0.0 & 6 \\
\hline Convenience foods & 266 & 78.9 & 22 & 95.5 & 0.0 & 0 \\
\hline Sauces and condiments & 310 & 81.9 & 19 & 81.9 & 0.0 & 0 \\
\hline Fish products and dishes & 85 & $40 \cdot 0$ & 3 & $36 \cdot 5$ & 0.0 & 0 \\
\hline Snack foods & 155 & $78 \cdot 1$ & 17 & $78 \cdot 1$ & 0.0 & 0 \\
\hline Special foods incl. meal replacements & 131 & $74 \cdot 0$ & 28 & $74 \cdot 0$ & 0.0 & 0 \\
\hline Egg products and dishes & 22 & 0.0 & 0 & 0.0 & 0.0 & 0 \\
\hline Confectionery & 834 & $98 \cdot 1$ & 42 & $95 \cdot 3$ & 1.2 & 10 \\
\hline Sugar products and dishes & 55 & $85 \cdot 5$ & 15 & $81 \cdot 8$ & $3 \cdot 6$ & 2 \\
\hline Miscellaneous & 15 & $60 \cdot 0$ & 10 & $60 \cdot 0$ & 0.0 & 0 \\
\hline Vitamins and supplements & 8 & $25 \cdot 0$ & 3 & $12 \cdot 5$ & $12 \cdot 5$ & 1 \\
\hline TOTAL & 5744 & 71.3 & 26 & $70 \cdot 8$ & 0.5 & 29 \\
\hline
\end{tabular}


into major food categories, high-fructose corn syrup was found primarily in confectionery products. These findings highlight the differences in Australian and US agricultural crops. The Australian sugar industry produces raw and refined sugar from sugarcane and contributes over \$AU 1 billion to the national economy ${ }^{(21)}$. This differs from the USA, where corn is the top agricultural crop in the country, representing \$US 63.9 billion $^{(30)}$. Furthermore, US cane sugar quotas, introduced to protect local industries, increased the price of sugar, thereby resulting in corn syrup and high-fructose corn syrup being much less expensive than using cane and beet sugar ${ }^{(31)}$.

The present study is the first to identify the major types of added sugars and non-nutritive sweeteners in a large sample of packaged Australian foods, although there are some limitations to the analysis. The data analysis process required sweeteners in ingredients lists to be spelled correctly for them to be identified in the Excel search function. Despite quality assurance checks applied, human error may still have occurred. Further, the process of using of a double filter and overriding those misidentified foods was also a manual process but the researchers believe the technique utilized is the most effective way to capture information about added sugars and sweeteners from ingredients lists. It is also important to note that the current analysis reflects only foods that were available for purchase, and does not provide information on actual consumer purchasing behaviours, which is an important component to consider for future research in this area.

Although not quantified, a continued investigation into the use of added sugars and non-nutritive sweeteners in packaged foods using the approach outlined in the present study may inform the development of practical policy recommendations. Such recommendations will enable consumers to make more informed food choices in accordance with dietary guidelines. Results could also be used to advocate for better food labelling regulations. Enforcing manufacturers to display the amount of added sugars on the Nutrition Information Panel has been recently legislated in the USA. From May 2016, food labels in the USA now require added sugar to be displayed in grams and as Percent Daily Value in line with the growing scientific evidence base for the Dietary Guidelines for Americans ${ }^{(32)}$.

Although the foods included in the present study were not selected to be representative of the Australian food supply, the authors believe selecting a random sample of foods contained in each of the seventeen FoodSwitch categories, including both core and non-core food items, gives a reasonable representation of Australian packaged foods. The study also considered the full range of approved sweeteners within the food supply at the time of investigation. The study aimed to determine the most common types of added sugars, which was found to be white sugar, as was hypothesized. The non-nutritive sweeteners were not common in the subset of packaged foods addressed, with only steviol glycoside appearing in the top three sweetening types for vitamin and supplement products only.

Finally, such investigations in Australia could increase the overall consumer understanding of the most common types of added sugars and non-nutritive sweeteners in Australian packaged foods.

\section{Acknowledgements}

Financial support: This research received no specific grant from any funding agency in the public, commercial or notfor-profit sectors. E.K.D. is supported by a National Health and Medical Research Council Early Career Fellowship. Conflict of interest: None. Authorship: The research question and study design were formulated by Y.C.P., J.C.Y.L. and E.K.D.; the study was carried out by Y.C.P., A.D. and J.J.; data analysis was carried out by Y.C.P., A.D. and J.J.; and the article was written by all authors with editing by Y.C.P., J.C.Y.L. and E.K.D. Ethics of buman subject participation: Not applicable.

\section{Supplementary material}

To view supplementary material for this article, please visit https://doi.org/10.1017/S136898001700218X

\section{References}

1. US Department of Agriculture (2014) What are added sugars? https://www.choosemyplate.gov/what-are-addedsugars (accessed April 2017).

2. Ng SW, Slining MM \& Popkin BM (2012) Use of caloric and noncaloric sweeteners in US consumer packaged foods, 2005-2009. J Acad Nutr Diet 112, 1828-1834.

3. Forshee RA \& Storey ML (2001) The role of added sugars in the diet quality of children and adolescents. J Am Coll Nutr 20, 32-43.

4. Australian Bureau of Statistics (1995) National Nutrition Survey: Selected Highlights, Australia, 1995. http://www.abs. gov.au/ausstats/abs@.nsf/mf/4802.0 (accessed April 2017).

5. Australian Bureau of Statistics (2011) Overweight and Obesity in Adults in Australia: A Snapshot, 2007-08. http:// www.abs.gov.au/AUSSTATS/abs@.nsf/DetailsPage/4842.0. 55.0012007\%E2\%80\%9308?OpenDocument (accessed April 2017).

6. World Health Organization (2014) Draft Guideline: Sugars intake for adults and children. http://www.who.int/nutrition/ sugars_public_consultation/en/ (accessed April 2017).

7. Jones ME, Barclay AW, Brand-Miller JC et al. (2016) Dietary glycaemic index and glycaemic load among Australians children and adolescents - results from the 2011-2012 Australian Health Survey. Br J Nutr 116, 178-187.

8. Louie JC \& Tapsell LC (2015) Association between intake of total vs added sugar on diet quality: a systematic review. Nutr Rev 73, 37-57.

9. Van Horn L, Johnson RK, Flickinger BD et al. (2010) Translation and implementation of added sugars consumption recommendations: a conference report from the American Heart Association Added Sugars Conference 2010. Circulation 122, 2470-2490. 
10. National Health and Medical Research Council of Australia (2013) Australian Dietary Guidelines (2013). https://www. nhmrc.gov.au/guidelines-publications/n55 (accessed April 2017).

11. Food Standards Australia New Zealand (2015) Nutrition Information Panels. http://www.foodstandards.gov.au/ consumer/labelling/panels/Pages/default.aspx (accessed April 2017).

12. Sigman-Grant $M \&$ Morita J (2003) Defining and interpreting intakes of sugars. Am J Clin Nutr 78, issue 4, 815S-826S.

13. Food Standards Australia New Zealand (2004) Consumption of intense sweeteners in Australia and New Zealand: Benchmark survey 2003. https://www.foodstandards.gov. $\mathrm{au} /$ publications/documents/Intense_sweetener_Report_ feb04.pdf (accessed April 2017).

14. Fowler SP, Williams K, Resendez RG et al. (2008) Fueling the obesity epidemic? Artificially sweetened beverage use and long-term weight gain. Obesity (Silver Spring) 16, 1894-1900.

15. Rogers PJ, Hogenkamp PS, de Graaf C et al. (2016) Does low-energy sweetener consumption affect energy intake and body weight? A systematic review, including metaanalyses, of the evidence from human and animal studies. Int J Obes (Lond) 40, 381-394.

16. Dhingra R, Sullivan L, Jacques PF et al. (2007) Soft drink consumption and risk of developing cardiometabolic risk factors and the metabolic syndrome in middle-aged adults in the community. Circulation 116, 480-488.

17. Fung TT, Malik V, Rexrode KM et al. (2009) Sweetened beverage consumption and risk of coronary heart disease in women. Am J Clin Nutr 89, 1037-1042.

18. Sylvetsky AC, Brown RJ, Blau JE et al. (2016) Hormonal responses to non-nutritive sweeteners in water and diet soda. Nutr Metab (Lond) 13, 71.

19. Pepino MY \& Bourne C (2011) Non-nutritive sweeteners, energy balance, and glucose homeostasis. Curr Opin Clin Nutr Metab Care 14, 391-395.

20. Swithers SE (2013) Artificial sweeteners produce the counterintuitive effect of inducing metabolic derangements. Trends Endocrinol Metab 24, 431-441.

21. Australian Department of Agriculture and Water Resources (2015) Sugar. http://www.agriculture.gov.au/ag-farm-food/ crops/sugar (accessed April 2017).
22. The George Institute for Global Health Australia (2016) FoodSwitch. http://www.georgeinstitute.org.au/projects/ foodswitch (accessed April 2017).

23. Dunford E, Trevena H, Goodsell C et al. (2014) FoodSwitch: a mobile phone app to enable consumers to make healthier food choices and crowdsourcing of national food composition data. JMIR mHealth uHealth 2, e37.

24. Food Standards Australia New Zealand (2005) Food labels: What do they mean? http://www.foodstandards.gov.au/ consumer/labelling/documents/Food\%20Labels\%20Poster final\%20.pdf (accessed April 2017).

25. Food Standards Australia New Zealand (2013) Ingredient Labelling of Foods User Guide to Standard 1.2.4 - Labelling of Ingredients. http://www.foodstandards.gov.au/code/ userguide/Documents/Guide\%20to\%20Standard\%201.2.4\% 20-\%20Ingredient\%20Labelling\%20of\%20Foods.pdf (accessed April 2017)

26. Cobiac L, Record S, Leppard P et al. (2003) Sugars in the Australian diet: results from the 1995 National Nutrition Survey. Nutr Diet 60, 152-173.

27. Brisbois TD, Marsden SL, Anderson GH et al. (2014) Estimated intakes and sources of total and added sugars in the Canadian diet. Nutrients 6, 1899-1912.

28. Thompson FE, McNeel TS, Dowling EC et al. (2009) Interrelationships of added sugars intake, socioeconomic status, and race/ethnicity in adults in the United States: National Health Interview Survey, 2005. J Am Diet Assoc 109, 1376-1383.

29. Acton RB, Vanderlee L, Hobin EP et al. (2017) Added sugar in the packaged foods and beverages available at a major Canadian retailer in 2015: a descriptive analysis. CMAJ Open 5, E1-E6.

30. US Environmental Protection Agency (2015) Major crops grown in the United States. https://www.epa.gov/sites/ production/files/2015-07/documents/ag_101_agriculture_us_ epa_0.pdf (accessed April 2017).

31. US Department of Agriculture, Economic Research Service (2017) Sugar and Sweeteners. https://www.ers.usda.gov/ topics/crops/sugar-sweeteners/ (accessed April 2017).

32. US Food and Drug Administration (2017) Changes to the Nutrition Facts Label. https://www.fda.gov/Food/Guidance Regulation/GuidanceDocumentsRegulatoryInformation/Label ingNutrition/ucm385663.htm (accessed April 2017). 